These points of scepticism should not detract from the many things that are right and important about this analysis and about the GBD project as a whole. And it is also clear that the GBD investigators are aware of these challenges and continually seeking ways to improve their models and move, iteratively, towards a clearer view of the truth. Globally, progress is being made to reduce diarrhoeal disease. If the GBD data could be used to also identify areas where data are particularly thin or dated, and so reduce uncertainties in the case of individual countries, that also would be a huge advance. As child survival researchers, we are hugely encouraged by this report, even as it reminds us that there are roughly 1.3 million excellent reasons why our job remains incomplete.

*ChristopherJ Gill, Donald M Thea, Patricia Hibberd Department of Global Health, Boston University School of Public Health, Boston, MA 02118, USA

cgill@bu.edu

Copyright $($ The Author(s). Published by Elsevier Ltd. This is an Open Access article under the CC BY NC-ND 4.0 license.

1 GBD 2015 Mortality and Causes of Death Collaborators. Global, regional and national life expectancy, all-cause mortality, and cause-specific mortality for 249 causes of death, 1980-2015: a systematic analysis for the Global Burden of Disease Study 2015. Lancet 2016; 388: 1459-1544.
2 GBD Diarrhoeal Diseases Collaborators. Estimates of global, regional, and national morbidity, mortality, and aetiologies of diarrhoeal diseases: a systematic analysis for the Global Burden of Disease Study 2015. Lancet Infect Dis 2017; published online June 1. http://dx.doi.org/10.1016/ S1473-3099(17)30276-1.

3 Kotloff KL, Nataro JP, Blackwelder WC, et al. Burden and aetiology of diarrhoeal disease in infants and young children in developing countries (the Global Enteric Multicenter Study, GEMS): a prospective, case-control study. Lancet 2013; 382: 209-22.

4 Walker CL, Rudan I, Liu L, et al. Global burden of childhood pneumonia and diarrhoea. Lancet 2013; 381: 1405-16.

5 Kelly SL, Wilson DP. GBD 2015 and HIV estimates from the Optima model. Lancet HIV 2016; 3: e558.

6 Byass P. Cause-specific mortality findings from the Global Burden of Disease project and the INDEPTH Network. Lancet Glob Health 2016; 4: e785-86

7 Liu L, Black RE, Cousens S, Mathers C, Lawn JE, Hogan DR. Causes of child death: comparison of MCEE and GBD 2013 estimates. Lancet 2015; 385: 2461-62.

8 IHME. Global health data exchange. 2017. http://ghdx.healthdata.org/ (accessed May 10, 2017).

9 Pacque-Margolis S, Pacque M, Dukuly Z, Boateng J, Taylor HR Application of the verbal autopsy during a clinical trial. Soc Sci Med 1990 31: 585-91.

10 Becker SR, Thornton JN, Holder W. Infant and child mortality estimates in two counties of Liberia: 1984. Int J Epidemiol 1993; 22 (suppl 1): S42-49.

11 WHO. Health statistics and information systems. Disease and injury country estimates. 2017. http://www.who.int/healthinfo/global_burden disease/estimates_country/en/ (accessed May 20, 2017)

12 Vos T, Barber R, Phillips DE, Lopez AD, Murray CJ. Causes of child death: comparison of MCEE and GBD 2013 estimates-Authors' reply. Lancet 2015; 385: 2462-64

13 Kassebaum NJ, Wang H, Lopez AD, Murray C), Lozano R. Maternal mortality estimates-Authors' reply. Lancet 2014; 384: 2211-12.

\title{
Dengue infection during pregnancy and risk of preterm birth
}

Studies that investigate dengue among pregnant women are rare. Although there is a high incidence of dengue infection in women of childbearing age, ${ }^{1}$ the effects of dengue infection during pregnancy on fetal outcomes are neither well understood nor well documented. ${ }^{2}$ Since the first reported case of a pregnant woman with dengue fever in 1948 , little evidence has been consolidated. ${ }^{2,3}$ Now, with increased recognition of dengue cases among adults, including women of reproductive age, and the association of Zika virus with congenital malformations, establishment of reference data is necessary for future analysis of trends on birth outcomes.

As reported in The Lancet Infectious Diseases, Laura Nascimento and colleagues ${ }^{4}$ used the extensive database of the Brazilian Ministry of Health to evaluate a retrospective cohort of 56817 suspected cases of dengue infection in pregnant women from 2007 to 2013. The databases used were the national reportable disease information system (SINAN), a consolidated system of passive registration for suspected dengue cases in Brazil since the 1990s, and the livebirth information system (SINASC), a database of birth registration. The authors referenced and briefly reviewed the information obtained from SINAN and SINASC in previously published studies. ${ }^{5,6}$ In Brazil, which contributes to up to $7 \%$ of annual dengue cases worldwide, successive dengue epidemics have occurred since 1986 and all four serotypes of dengue virus are in circulation.

From 56817 reported cases of dengue in pregnant women, the authors analysed 3898 laboratoryconfirmed cases and 3165 dengue-negative cases linked with livebirth data. Besides comparing maternal characteristics, the authors estimated relative risks (RRs) and odds ratios (ORs) between the groups with and without dengue infection and stratified by gestational age for different outcomes: malformation, preterm births, and low birthweight. Maternal

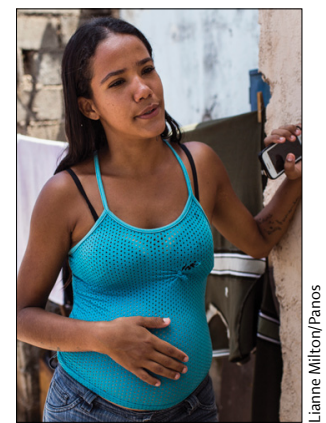

Published Online May 18, 2017 http://dx.doi.org/10.1016 S1473-3099(17)30298-0 See Articles page 949 
dengue infection was associated with an increased incidence of preterm birth (adjusted analysis: OR 1.26, 95\% Cl 1.06-1.49, $p=0.006$; unadjusted analysis: RR 0.81, 95\% Cl 0.70-0.93, p=0.004). Notably, after adjusting for covariates, the direction of the effect changed, suggesting that both the risk of dengue acquisition and the quality of adequate prenatal care depend strongly on demographic and socioeconomic determinants. The authors found no association between dengue infection and low birthweight and congenital malformations, confirming previous findings of smaller studies. ${ }^{2}$ This is the largest dengue population studied so far, which provides baseline data before the introduction of chikungunya and Zika viruses to the country.

Although secondary databases have inherent limitations related to under-reporting of passive surveillance systems and data quality, in this study the analyses included comparison groups and a large sample size, which strengthened the results. Similar to most studies of this topic, this one was restricted to pregnant women with symptomatic dengue infection, introducing a potential bias because of the absence of asymptomatic infections, which could account for almost $50 \%$ of all infections. ${ }^{25,8-11}$ Additionally, dengue infection in pregnant women in the second and third trimester is more likely to be reported than in earlier periods of pregnancy and in women of reproductive age who might not know they are pregnant. The databases used did not permit adequate estimation of the role of dengue infection in miscarriages, especially those occurring during the first trimester of pregnancy. ${ }^{2}$

The association between preterm birth and dengue virus infection in pregnant woman is biologically plausible, because the intense inflammation reaction

\section{Dengue and stillbirth}

See Articles page 957 Dengue, a viral disease mostly transmitted by Aedes aegypti, is widespread in tropical and subtropical regions of Africa, the Americas, Asia, and Oceania. ${ }^{1}$ The incidence of dengue is increasing in many areas, with more than half of the world's population now vulnerable. ${ }^{2}$ Many dengue infections are subclinical, but others present with symptoms including high fever, headache, weakness, muscle pain, and sometimes a rash that usually diminish after 6 days. At its worst, dengue triggered by maternal infection can indirectly stimulate uterine contractions leading to preterm delivery. ${ }^{2,3,5,11}$ Since prematurity is among the main causes of neonatal and infant death, ${ }^{2}$ we recommend close monitoring of pregnancies in areas with concurrent circulation of several arboviruses and where differentiating between dengue, Zika, and chikungunya virus infections is challenging.

*Patrícia Brasil, Otilia Lupi

Instituto Nacional de Infectologia Evandro Chagas, Fiocruz, Rio de Janeiro 21.040-360, Brazil

patricia.brasil@ini.fiocruz.br

We declare no competing interests.

1 Simmons CP, Farrar JJ, Nguyen VV, Wills B. Dengue. N EnglJ Med 2012; 366: 1423-32.

2 Paixão ES, Teixeira MG, da Conceição N Costa M, Rodrigues LC. Dengue during pregnancy and adverse fetal outcomes: a systematic review and meta-analysis. Lancet Infect Dis 2016; 16: 857-65.

3 Ribeiro CF, Lopes VG, Brasil P, Pires AR, Rohloff R, Nogueira RM Dengue infection in pregnancy and its impact on the placenta. Int J Infect Dis 2017; 55: 109-12.

4 Nascimento LB, Siqueira CM, Coelho GE, Siqueira JB Jr. Symptomatic dengue infection during pregnancy and livebirth outcomes in Brazil, 2007-13: a retrospective observational cohort study. Lancet Infect Dis 2017 published online May 18. http://dx.doi.org/10.1016/S14733099(17)30169-X.

5 Machado CR, Machado ES, Rohloff RD, et al. Is pregnancy associated with severe dengue? A review of data from the Rio de Janeiro surveillance information system. PLoS Negl Trop Dis 2013; 7: e2217.

6 de Frias PG, Szwarcwald CL, de Lira PIC. Avaliação dos sistemas de informações sobre nascidos vivos e óbitos no Brasil na década de 2000 Cad Saude Publica 2014; 30: 2068-280.

7 Messina JP, Brady OJ, Scott TW, et al. Global spread of dengue virus types: mapping the 70 years history. Trends Microbiol 2014; 22: 138-46.

8 Restrepo BN, Isaza DM, Salazar CL, et al. Dengue y embarazo em Antioquia Colombia. Revista Facultad Nacional de Salud Pública 2004; 22: 7-14.

9 Adam I, Jumaa AM, Elbashir HM, Karsany MS. Maternal and perinatal outcomes of dengue in Port-Sudan, Eastern Sudan. Virol J 2010; 7: 153

10 Tan PC, Soe MZ, Si Lay K, Wang SM, Sekaran SD, Omar SZ. Dengue infection and miscarriage: a prospective case control study. PLoS Negl Trop Dis 2012; 6: e1637.

11 Friedman EE, Dallah F, Harville EW, et al. Symptomatic dengue infection during pregnancy and infant outcomes: a retrospective cohort study. PLoS Negl Trop Dis 2014; 8: e3226.

might cause dengue haemorrhagic fever or dengue shock syndrome, resulting in death. Generally, dengue infection is more harmful to vulnerable populations and is a leading cause of serious illness and death among children in some Asian and Latin American countries. ${ }^{3,4}$

Preterm birth and low birthweight are the most common adverse pregnancy outcomes associated with maternal dengue infection. ${ }^{3}$ However, several case reports $s^{5-7}$ have suggested that the dengue virus can be 